\title{
Prevalence of Dirofilaria immitis, Ehrlichia canis, Borrelia burgdorferi sensu lato, Anaplasma spp. and Leishmania infantum in apparently healthy and CVBD-suspect dogs in Portugal - a national serological study
}

Luís Cardoso ${ }^{1,2^{*}+}$, Cláudio Mendão ${ }^{3+}$ and Luís Madeira de Carvalho ${ }^{4+}$

\begin{abstract}
Background: Canine vector-borne diseases (CVBDs) are caused by a wide range of pathogens transmitted to dogs by arthropods including ticks and insects. Many CVBD-agents are of zoonotic concern, with dogs potentially serving as reservoirs and sentinels for human infections. The present study aimed at assessing the seroprevalence of infection with or exposure to Dirofilaria immitis, Ehrlichia canis, Borrelia burgdorferi sensu lato, Anaplasma spp. and Leishmania infantum in dogs in Portugal.

Methods: Based on 120 veterinary medical centres from all the regions of mainland and insular Portugal, 557 apparently healthy and 628 CVBD-suspect dogs were sampled. Serum, plasma or whole blood was tested for qualitative detection of D. immitis antigen and antibodies to E. canis, B. burgdorferi s. I., Anaplasma spp. and L. infantum with two commercial in-clinic enzyme-linked immunosorbent assay kits. Odds ratios (OR) were calculated by logistic regression analysis to identify independent risk factors of exposure to the vector-borne agents.

Results: Total positivity levels to D. immitis, E. canis, B. burgdorferi, Anaplasma spp., L. infantum, one or more agents and mixed agents were $3.6 \%, 4.1 \%, 0.2 \%, 4.5 \%, 4.3 \%, 14.0 \%$ and $2.0 \%$ in the healthy group, and $8.9 \%, 16.4 \%, 0.5 \%$, $9.2 \%, 25.2 \%, 46.3 \%$ and $11.6 \%$ in the clinically suspect group, respectively. Non-use of ectoparasiticides was a risk factor for positivity to one or more agents both in the apparently healthy $(O R=2.1)$ and CVBD-suspect $(O R=1.5)$ dogs. Seropositivity to $L$. infantum $(O R=7.6)$, E. canis $(O R=4.1)$ and $D$. immitis $(O R=2.4)$ were identified as risk factors for the presence of clinical signs compatible with CVBDs. Positivity to mixed agents was not found to be a risk factor for disease.

Conclusions: Dogs in Portugal are at risk of becoming infected with vector-borne pathogens, some of which are of zoonotic concern. CVBDs should be considered by practitioners and prophylactic measures must be put in place to protect dogs and limit the risk of transmission of vector-borne agents to humans. This study is expected to give veterinary and public health authorities an increased awareness about CVBDs in Portugal and to serve as a reference for future investigations and control actions.
\end{abstract}

Keywords: Anaplasma spp., Borrelia burgdorferi sensu lato, Canine Vector-Borne Diseases, Dogs, Dirofilaria immitis, Ehrlichia canis, Epidemiology, In-Clinic ELISA Tests, Leishmania infantum, Portugal

\footnotetext{
* Correspondence: Icardoso@utad.pt

+ Contributed equally

'Department of Veterinary Sciences, School of Agrarian and Veterinary

Sciences, University of Trás-os-Montes e Alto Douro, Vila Real, Portugal

Full list of author information is available at the end of the article
} 


\section{Background}

Canine vector-borne diseases (CVBDs) are an emerging problem worldwide due to their frequency and morbidity and, in most cases, also to their zoonotic relevance, with dogs potentially serving as sentinels for human infection [1]. CVBDs are caused by a diverse range of pathogens, mainly bacteria and parasites, which are transmitted to dogs by different arthropod vectors, particularly ticks and insects [2].

Nematode Dirofilaria immitis, bacteria Ehrlichia canis, Borrelia burgdorferi sensu lato, Anaplasma phagocytophilum and Anaplasma platys, and protozoan Leishmania infantum are among of the major vector-borne agents that can infect dogs [3].

D. immitis is transmitted by mosquitoes primarily from genera Culex, Aedes and Anopheles, and causes dirofilariosis or heartworm disease, a potentially fatal condition in dogs [4]. Canine dirofilariosis is associated with a dry chronic cough, exercise intolerance, dyspnoea, weakness, weight loss, epistaxis, cyanosis and congestive heart failure [5]. Dogs are the natural hosts, but infection may also occur in other canids and cats, and there is also a risk of zoonotic transmission [6]. Human heartworm infections are relatively uncommon; nevertheless, $D$. immitis can cause pulmonary dirofilariosis in people with the occurrence of granulomas in the lungs $[7,8]$.

E. canis, a causative agent of acute or chronic canine monocytic ehrlichiosis, is transmitted by the brown dog tick, Rhipicephalus sanguineus [9]. Dogs infected with $E$. canis present a spectrum of disease that ranges from subclinical infection to fatal illness [10]. Clinical signs often include lethargy, anorexia, weight loss, hyperthermia, epistaxis and other haemorrhagic disorders, pale mucous membranes and lymph node enlargement [11]. E. canis has a zoonotic potential as human infections have been reported from Venezuela [12].

B. burgdorferi s.l. spirochetes infect mammals, including dogs and human beings, and cause the so-called Lyme disease [13]. In Europe, Ixodes ricinus ticks are important vectors of B. burgdorferi s.l. [9]. Most people exposed to $B$. burgdorferi show mild non-specific symptomatology, but Lyme borreliosis can be a chronic debilitating disease in humans, with arthritis, skin changes and neurological or cardiac dysfunction [14]. In contrast, relatively few infected dogs demonstrate clinical signs. However, canine borreliosis has been associated with lethargy, hyperthermia, anorexia, joint inflammation, lameness, lymphadenopathy and glomerulonephritis [15].

A. phagocytophilum, the agent of granulocytic anaplasmosis, is vectored in Europe by I. ricinus and can infect a wide range of domestic and wild vertebrate hosts, including rodents, horses, dogs and humans [16].
Infection in dogs may be subclinical or result in a mild to severe acute illness, with lethargy, anorexia, hyperthermia, lameness and, occasionally, polydipsia, vomiting, diarrhoea and even neurologic signs [17]. In human beings $A$. phagocytophilum induces a febrile syndrome associated with myalgia and headache, and is considered an emerging pathogen [18].

$A$. platys is a bacterium primarily of dogs that infects platelets and may cause canine infectious cyclic thrombocytopenia [16]. Clinical signs include abnormalities such as lymphadenomegaly and pale mucous membranes, but canine infections with A. platys are mostly subclinical [19]. Although its virulence is generally low, $A$. platys might play a role in co-infection with other vector-borne agents [9]. The presumed vector of $A$. platys is $R$. sanguineus.

Dogs are the main reservoir of L. infantum, which is transmitted among canines and to humans by phlebotomine sand fly insects, Phlebotomus spp. in Europe [20]. Canine leishmaniosis is a systemic chronic condition whose clinical manifestations usually include lymphadenopathy, dermatitis, alopecia, cutaneous ulceration, onychogryphosis, lameness, weight loss, cachexia, ocular lesions, epistaxis, anaemia and renal failure [21]. A large majority of the infected dogs do not develop clinical signs but they may still be capable of transmitting the parasite to the vectors [22]. In people, visceral leishmaniosis is the most severe clinical syndrome resulting from infections with L. infantum, and in Europe it is observed mainly in children and immunocompromised adults [23]. Leishmaniosis due to L. infantum is a major zoonosis potentially fatal to dogs and humans, and infected dogs represent an important veterinary medical and public health problem [24].

Dogs can be sequentially or simultaneously infected with more than one vector-borne agent by being exposed to arthropods infected with a single pathogen species or to vector(s) concurrently infected with different organisms $[2,25]$. Some arthropod species, particularly ticks, act as vectors of more than one agent and co-infection of individual arthropods can occur [9]. Awareness of canine co-infections is an important clinical and diagnostic issue as they might induce more severe pathological effects than infections with either agent alone [26].

Diagnosis and screening are essential for the control of CVBDs, both at the individual and population levels, with detection methods including cytological examination of blood smears or other tissues, serology (for antibodies or antigens) and the polymerase chain reaction (PCR). Evidence of infection with or exposure to the causative agents of dirofilariosis, ehrlichiosis, borreliosis, anaplasmosis and leishmaniosis can be assessed via rapid in-clinic serological testing [27]. Results of either 
single or co-infections must be interpreted in combination with data on the geographical origin, history of vector exposure and clinical status of dogs, along with other confirmatory tests [28].

Environmental changes, especially global warming, have an impact on the arthropods geographical distribution, abundance and vectorial capacity [29]. Together with human and animal population dynamics, including the increased mobility of dogs, climatic changes may affect the occurrence and spread of CVBDs [2]. Updated information on the epidemiology of infection and disease is required to map regional risk, identify new areas of endemicity and forecast CVBD scenarios [30].

D. immitis, E. canis, B. burgdorferi s. 1., A. phagocytophilum, A. platys and L. infantum have been detected in Portugal in dogs and/or arthropods [31,32]. Nevertheless, except for the latter [33], there is no comprehensive data available on the regional distribution and prevalence of these vector-borne agents at the countrywide level. The present study aimed at assessing the seroprevalence of infection with or exposure to $D$. immitis, $E$. canis, B. burgdorferi s. l., Anaplasma spp. and L. infantum in healthy and CVBD-suspect dogs in Portugal.

\section{Methods}

\section{Veterinary medical centres and dogs}

This study was based on a convenience sample of 120 veterinary medical centres from all the Portuguese NUTS (Nomenclature of Units for Territorial Statistics) regions that represented $\sim 15 \%$ of the veterinary centres in the country. Point-of-care tests were delivered to 28 centres in the North, 24 in the Centre, 20 in Alentejo, 27 in Lisbon, 19 in the Algarve, one in the Azores and another one in Madeira (Figure 1). Based on a physical examination, local veterinarians were asked to randomly seek for 5 apparently healthy dogs and 5 dogs clinically suspect of a vector-borne disease, including dirofilariosis, ehrlichiosis, borreliosis, anaplasmosis or leishmaniosis.

Suspect or symptomatic dogs had at least one clinical sign of disease, including alopecia, anorexia, cutaneous ulceration, cyanosis, dermatitis, diarrhoea, dry chronic cough, dyspnoea, epistaxis, exercise intolerance, haemorrhagic disorders, hyperthermia, joint inflammation, lameness, lethargy, lymph node enlargement, neurologic signs, ocular lesions, onychogryphosis, pale mucous membranes, polydipsia, vomiting, weakness and weight loss. Healthy or asymptomatic dogs had no signs or historical abnormalities.

From October 2010 to April 2011, 557 apparently healthy dogs and 628 CVBD-suspect dogs were sampled with oral consent from owners. Information was recorded on the animals' gender, age, lifestyle (indoors versus outdoors or mixed), detectable tick infestation,

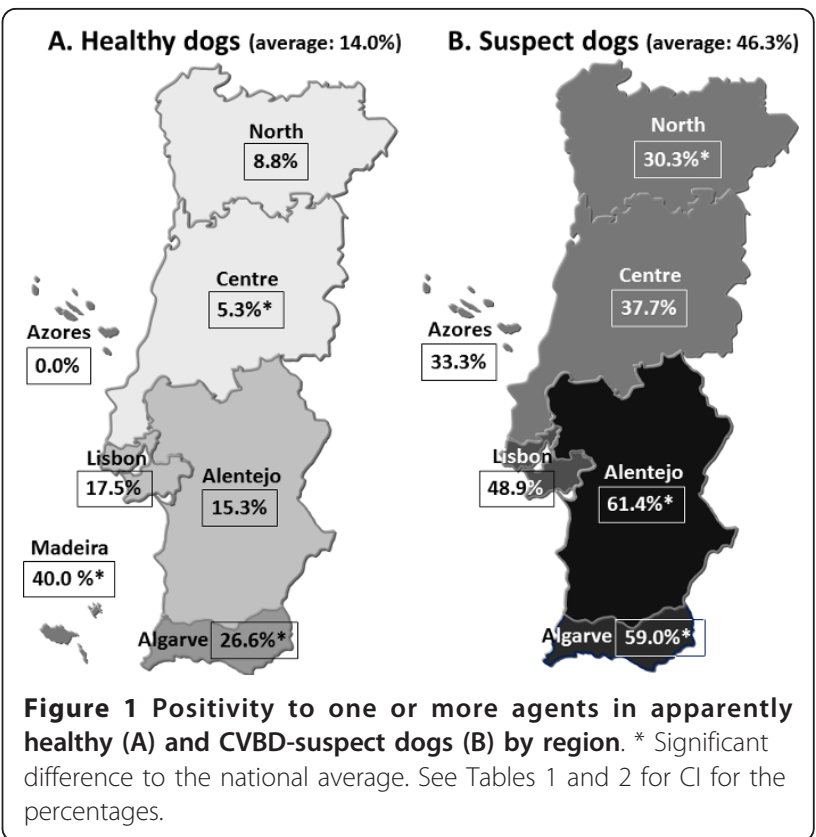

use of ectoparasiticides (acaricides and/or insecticides) and NUTS where they lived. Travel histories were not available.

In the healthy group there were 269 females and 288 males. Median age was 5.0 years (interquartile range [IQR]: 2.0-8.0); age was not recorded for 2 dogs. There were 61 animals aged 12 months or less and 494 older than 12 months. Sixty-five dogs had an indoor lifestyle and $562 \mathrm{had}$ an outdoor or mixed one. There were no detectable ticks in 535 dogs, while 22 had ticks. Ectoparasiticides were used on 371 but not on 168 dogs; no information was available from 18 animals. The numbers of apparently healthy dogs sampled by NUTS are shown in Table 1.

Among the CVBD-suspect dogs there were 262 females and 366 males. Median age was 6.0 years (IQR: 3.0-9.0); age was not recorded for 2 animals. Forty-five dogs had 12 months or less and 581 were older than 12 months. Seventy dogs had an indoor lifestyle and 487 had an outdoor or mixed lifestyle; no information was available from one animal. There were no detectable ticks in 577 dogs, while 51 had ticks. Ectoparasiticides were used on 302 but not on 270 dogs; no information was available from 56 animals. The numbers of clinically suspect dogs sampled by NUTS are shown in Table 2 .

\section{Testing for serum antigen and antibodies}

Serum, plasma or whole blood samples from dogs were screened for simultaneous qualitative detection of circulating $D$. immitis antigen and antibodies, both immunoglobulin $\mathrm{G}$ and $\mathrm{M}$, to E. canis, B. burgdorferi sensu lato and Anaplasma spp. with SNAP ${ }^{\circledR} 4 \mathrm{Dx}^{\circledR}$ test. The same 
Table 1 Prevalence of positivity to vector-borne agents in 557 apparently healthy dogs by Portuguese NUTS region

\begin{tabular}{|c|c|c|c|c|c|c|c|}
\hline $\begin{array}{l}\begin{array}{l}\text { Region } \\
\text { (n) }\end{array} \\
\end{array}$ & $\begin{array}{l}\text { D. immitis } \\
(95 \% \mathrm{Cl})\end{array}$ & $\begin{array}{l}\text { E. canis } \\
(95 \% \mathrm{Cl})\end{array}$ & $\begin{array}{l}\text { B. burgdorferi s.I. } \\
(95 \% \mathrm{Cl})\end{array}$ & $\begin{array}{l}\text { Anaplasma spp. } \\
(95 \% \mathrm{Cl})\end{array}$ & $\begin{array}{l}\text { L. infantum } \\
(95 \% \mathrm{Cl})\end{array}$ & $\begin{array}{l}\text { One or more agents } \\
(95 \% \mathrm{Cl})\end{array}$ & $\begin{array}{l}\text { Mixed agents } \\
(95 \% \mathrm{Cl})\end{array}$ \\
\hline orth (137) & 7.3) & 4.0) & & & $3.6 \%(1.2-8.3)$ & ( & $0.7 \%(0.0-4.0)$ \\
\hline Entre (113) & $0.9 \%(0.0-4.8)$ & $0.9 \%(0.0-4.8)$ & $0.0 \%(0.0-3.2)$ & $2.7 \%(0.6-7.6)$ & $0.9 \%(0.0-4.8)$ & $5.3 \% *(2.0-11.2)$ & $0.0 \%(0.0-3.2)$ \\
\hline Alentejo (85) & $4.7 \%(1.3-11.6)$ & $2.4 \%(0.3-8.2)$ & $1.2 \%(0.0-6.4)$ & $3.5 \%(0.7-10.0)$ & $5.9 \%(1.9-13.2)$ & $15.3 \%(8.4-24.7)$ & $1.2 \%(0.0-6.4)$ \\
\hline isbon (126) & $2.4 \%(0.5-6.8)$ & $6.3 \%(2.8-12.1)$ & $0.0 \%(0.0-29)$ & $6.3 \%(2.8-12.1)$ & $7.9 \%(3.9-14.1)$ & $17.5 \%(11.3-25.2)$ & $4.0 \%(1.3-9.0)$ \\
\hline Igarve (79) & $5.1 \%(1.4-12.5)$ & $13.9 \% *(7.2-23.5)$ & $0.0 \%(0.0-4.6)$ & $10.1 \% *(4.5-19.0)$ & $3.8 \%(0.8-10.7)$ & $26.6 \% *(17.3-37.7)$ & $5.1 \%(1.4-12.5)$ \\
\hline Azores (7) & $0.0 \%(0.0-41.0)$ & $0.0 \%(0.0-41.0)$ & $0.0 \%(0.0-41.0)$ & $0.0 \%(0.0-41.0)$ & $0.0 \%(0.0-41.0)$ & $0.0 \%(0.0-41.0)$ & $0.0 \%(0.0-41.0)$ \\
\hline Madeira (10) & $40.0 \% *(12.1-73.8)$ & $0.0 \%(0.0-30.8)$ & $0.0 \%(0.0-30.8)$ & $0.0 \%(0.0-30.8)$ & $0.0 \%(0.0-30.8)$ & $40.0 \% *(12.1-73.8)$ & $0.0 \%(0.0-30.8)$ \\
\hline tal (557) & $3.6 \%(2.2-5.5)$ & $4.1 \%(2.6-6.1)$ & $0.2 \%(0.0-1.0)$ & $4.5 \%(2.9-6.5)$ & $4.3 \%(2.8-6.3)$ & $14.0 \%(11.2-17.2)$ & $2.0 \%(1.0-3.5)$ \\
\hline
\end{tabular}

* Statistically significant difference $(p<0.05)$ to the corresponding national average value of prevalence.

samples were further qualitatively tested for antibodies to L. infantum with SNAP ${ }^{\circledR}$ Leishmania. These two rapid tests are commercially available in-clinic enzymelinked immunosorbent assay (ELISA) kit devices from IDEXX Laboratories (Westbrook, Maine, USA) and were operated according to the manufacturer's instructions listed in the product package insert.

The SNAP ${ }^{\circledR} 4 \mathrm{Dx}^{\circledR} D$. immitis analyte is derived from polyclonal antibodies specific to a carbohydrate antigen of the adult female heartworms [34]. The commercially available in-clinic ELISA detects antibodies against peptides from p30 and p30-1 outer membrane immunodominant proteins of E. canis [35]. The B. burgdorferi s. 1. analyte detects antibodies specific to the $\mathrm{C}_{6}$ synthetic peptide derived from the IR6 region within the Borrelia membrane protein VlsE [36]. This peptide does not react with antibodies elicited following $B$. burgdorferi vaccination [37]. The Anaplasma spp. analyte detects antibodies reacting to a synthetic peptide derived from the immunodominant major outer surface protein (p44/ MSP2) of A. phagocytophilum [38]. Preliminary studies indicate that the A. phagocytophilum analyte in $\mathrm{SNAP}^{\mathbb{B}}$ $4 \mathrm{Dx}{ }^{\circledR}$ cross-reacts with samples from $A$. platys infected dogs $\left(\mathrm{SNAP}^{\circledR} 4 \mathrm{Dx}^{\circledR}\right.$ kit insert, unpublished observations) [27]. The antigen used in $\operatorname{SNAP}^{\circledR}$ Leishmania is derived from $L$. infantum promastigotes prepared by sonic disruption, filtration and diethylaminoethyl column purification [39].

Reported sensitivities/specificities of the $\mathrm{SNAP}^{\circledR} 4 \mathrm{Dx}^{\circledR}$ test are $99.2 \% / 100 \%$ for $D$. immitis, $96.2 \% / 100 \%$ for $E$. canis, $98.8 \% / 100 \%$ for B. burgdorferi s. 1. and $99.1 \% /$ $100 \%$ for A. phagocytophilum [34]. Sensitivity and specificity of SNAP ${ }^{\circledR}$ Leishmania were $91.1 / 93.4 \%$ and $98.3 /$ $99.2 \%$, respectively compared with an immunofluorescence antibody test (IFAT) or Western blot [39].

\section{Data analysis}

Exact binomial test was used to calculate confidence intervals (CI) for the proportions, with a $95 \%$ confidence level. Chi-square and Fisher's exact tests compared proportions of positivity (no. of dogs found positive divided by the no. of dogs tested) related to categorical dependent variables. Analyses were done with StatLib or SPSS 11.5 software for Windows. A probability $(p)$ value < 0.05 was regarded as statistically significant. Binomial variables showing a significant difference between

Table 2 Prevalence of positivity to vector-borne agents in 628 CVBD-suspect dogs by Portuguese NUTS region

\begin{tabular}{|c|c|c|c|c|c|c|c|}
\hline $\begin{array}{l}\text { Region } \\
\text { (n) }\end{array}$ & $\begin{array}{l}\text { D. immitis } \\
(95 \% \mathrm{Cl})\end{array}$ & $\begin{array}{l}\text { E. canis } \\
(95 \% \mathrm{Cl})\end{array}$ & $\begin{array}{l}\text { B. burgdorferi } \\
\text { s.l. } \\
(95 \% \mathrm{CI})\end{array}$ & $\begin{array}{l}\text { Anaplasma spp. } \\
(95 \% \mathrm{Cl})\end{array}$ & $\begin{array}{l}\text { L. infantum } \\
(95 \% \mathrm{Cl})\end{array}$ & $\begin{array}{l}\text { One or more } \\
\text { agents } \\
(95 \% \mathrm{Cl})\end{array}$ & $\begin{array}{l}\text { Mixed agents } \\
(95 \% \mathrm{Cl})\end{array}$ \\
\hline North (145) & $3.4 \% *(1.1-7.9)$ & $7.6 \% *(3.8-13.2)$ & $0.7 \%(0.0-3.8)$ & $5.5 \%(2.4-10.6)$ & $\begin{array}{l}18.6 \%(12.6- \\
25.9)\end{array}$ & $30.3 \% *(23.0-38.5)$ & $4.1 \% *(1.5-8.8)$ \\
\hline Centre (122) & $7.4 \%(3.4-13.5)$ & $9.0 \% *(4.6-15.6)$ & $0.8 \%(0.0-4.5)$ & $3.3 \% *(0.9-8.2)$ & $\begin{array}{l}25.4 \%(18.0- \\
34.1)\end{array}$ & $37.7 \%(29.1-46.9)$ & $7.4 \%(3.4-13.5)$ \\
\hline $\begin{array}{l}\text { Alentejo } \\
(114)\end{array}$ & $14.0 \%(8.2-21.8)$ & $\begin{array}{l}25.4 \% *(17.7- \\
34.4)\end{array}$ & $0.0 \%(0.0-3.2)$ & $9.6 \%(4.9-16.6)$ & $\begin{array}{l}27.2 \%(19.3- \\
36.3)\end{array}$ & $61.4 \% *(51.8-70.4)$ & $13.2 \%(7.6-20.8)$ \\
\hline Lisbon (139) & $5.8 \%(2.5-11.0)$ & $19.4 \%(13.2-27.0)$ & $0.7 \%(0.0-3.9)$ & $11.5 \%(6.7-18.0)$ & $\begin{array}{l}30.2 \%(22.7- \\
38.6)\end{array}$ & $48.9 \%(40.3-57.5)$ & $15.8 \%(10.2-23.0)$ \\
\hline Algarve (105) & $\begin{array}{l}17.1 \% *(10.5- \\
25.7)\end{array}$ & $23.8 \%(16.0-31.1)$ & $0.0 \%(0.0-3.4)$ & $\begin{array}{l}17.1 \% *(10.5- \\
25.7)\end{array}$ & $\begin{array}{l}25.7 \%(17.7- \\
35.2)\end{array}$ & $59.0 \% *(49.0-68.5)$ & $\begin{array}{l}20.0 \% \%^{*}(12.8- \\
28.9)\end{array}$ \\
\hline Azores (3) & $0.0 \%(0.0-70.8)$ & $0.0 \%(0.0-70.8)$ & $0.0 \%(0.0-70.8)$ & $33.3 \%(0.8-90.6)$ & $0.0 \%(0.0-70.8)$ & $33.3 \%(0.8-90.6)$ & $0.0 \%(0.0-70.8)$ \\
\hline Total (628) & $8.9 \%(6.8-11.4)$ & $16.4 \%(13.6-19.5)$ & $0.5 \%(0.1-1.4)$ & $9.2 \%(7.1-11.8)$ & $\begin{array}{l}25.2 \%(21.8- \\
28.7)\end{array}$ & $46.3 \%(42.4-50.3)$ & $11.6 \%(9.2-14.4)$ \\
\hline
\end{tabular}

* Statistically significant difference $(p<0.05)$ to the corresponding national average value of prevalence. 
categories were selected to univariate or multivariate logistic regression analysis to identify independent risk factors of exposure to the vector-borne agents, calculating odds ratios (OR) and their 95\% CI [40].

\section{Results}

Total and regional positivity of healthy dogs to the several vector-borne agents and to the parameters of one or more agents ( $\geq 1$ agent) and mixed agents $(\geq 2$ agents) are displayed in Table 1. A map of positivity to one or more agents by NUTS is further presented in Figure 1 (A). Risk factors identified in apparently healthy dogs are shown in Table 3.

Table 2 displays data on the total and regional positivity of clinically suspect dogs to the vector-borne agents and to the other two parameters. Figure 1 (B) shows a map with positivity to one or more agents by NUTS region. Table 4 presents risk factors identified in CVBDsuspect dogs.

In decreasing order, seropositivity to $L$. infantum (OR $=7.6,95 \%$ CI: $4.8-11.9 ; p<0.001)$, E. canis $(\mathrm{OR}=4.1$, 95\% CI: 2.5-6.7; $p<0.001)$ and D. immitis $(\mathrm{OR}=2.4$, 95\% CI: $1.4-4.2 ; p=0.002)$ were risk factors for the presence of clinical signs compatible with a CVBD. In univariate analysis, positivity to mixed agents was not found to be a risk factor for clinical signs; positivity to one or more agents was not assessed by logistic regression.

Table 5 describes positivity to single and mixed vector-borne agents among the apparently healthy and the clinically suspect dogs. No dog was positive for all agents; 479 healthy (86.0\%) and 337 suspect dogs $(53.7 \%)$ were negative for all five tests.

\section{Discussion}

This is the most comprehensive study carried out in Portugal on the prevalence of infection with or exposure to CVBD-agents regarding the diversity of pathogens and/or the geographical areas under assessment.

Table 3 Risk factors for E. canis, Anaplasma spp. and one or more agents in apparently healthy dogs

\begin{tabular}{llll}
\hline $\begin{array}{l}\text { Dependent variable/ } \\
\text { /risk factor }\end{array}$ & $\boldsymbol{p}$ value & OR & $\mathbf{9 5 \%} \mathbf{C l}$ \\
\hline $\begin{array}{l}\text { Positivity to E. canis } \\
\quad \text { Positivity to Anaplasma spp. }\end{array}$ & $<0.001$ & 20.8 & $7.9-55.1$ \\
$\begin{array}{l}\text { Positivity to Anaplasma spp. } \\
\quad \text { Detectable ticks }\end{array}$ & $=0.185$ & 2.7 & $0.6-11.4$ \\
$\quad$ Non-use of ectoparasiticides & $=0.079$ & 2.3 & $0.9-5.7$ \\
$\quad$ Positivity to E. canis & $<0.001$ & 20.7 & $7.4-58.1$ \\
Positivity to one or more agents & & & \\
$\quad$ Age $>12$ months & $=0.040$ & 3.5 & $1.1-11.5$ \\
$\quad$ Non-use of ectoparasiticides & $=0.004$ & 2.1 & $1.3-3.4$ \\
\hline
\end{tabular}

Table 4 Risk factors for positivity to vector-borne agents and combined parameters in CVBD-suspect dogs

\begin{tabular}{|c|c|c|c|}
\hline $\begin{array}{l}\text { Dependent variable/ } \\
\text { /risk factor }\end{array}$ & $p$ value & OR & $95 \% \mathrm{Cl}$ \\
\hline \multicolumn{4}{|l|}{ Positivity to $D$. immitis } \\
\hline Age $>12$ months & $=0.997$ & $1.5^{8}$ & $0.0-\mathrm{ND}$ \\
\hline Outdoor or mixed lifestyle & $=0.073$ & 6.2 & $0.8-46.1$ \\
\hline Positivity to E. canis & $=0.036$ & 2.0 & $1.0-3.7$ \\
\hline \multicolumn{4}{|l|}{ Positivity to E. canis } \\
\hline Age $>12$ months & $=0.088$ & 3.5 & $0.8-15.1$ \\
\hline Positivity to D. immitis & $=0.085$ & 1.8 & $0.9-3.5$ \\
\hline Positivity to Anaplasma spp. & $<0.001$ & 6.1 & $3.5-10.9$ \\
\hline \multicolumn{4}{|l|}{ Positivity to Anaplasma spp. } \\
\hline Non-use of ectoparasiticides & $=0.011$ & 2.2 & $1.2-4.2$ \\
\hline Positivity to E. canis & $<0.001$ & 7.4 & $4.0-13.5$ \\
\hline \multicolumn{4}{|l|}{ Positivity to L. infantum } \\
\hline Age $>12$ months & $=0.030$ & 2.7 & $1.1-7.4$ \\
\hline \multicolumn{4}{|l|}{ Positivity to one or more agents } \\
\hline Age $>12$ months & $<0.001$ & 4.2 & $1.9-9.3$ \\
\hline Outdoor or mixed lifestyle & $=0.004$ & 2.5 & $1.3-4.7$ \\
\hline Non-use of ectoparasiticides & $=0.022$ & 1.5 & $1.1-2.1$ \\
\hline \multicolumn{4}{|l|}{ Positivity to mixed agents } \\
\hline Age $>12$ months & $<0.001$ & 4.4 & $2.0-9.6$ \\
\hline Outdoor or mixed lifestyle & $=0.003$ & 2.4 & $1.4-4.3$ \\
\hline
\end{tabular}

ND: not defined.

Table 5 Positivity to single and mixed vector-borne agents among 557 apparently healthy and 628 CVBDsuspect dogs

\begin{tabular}{|c|c|c|c|c|}
\hline Agents & $\begin{array}{l}\text { Healthy } \\
\text { (n) }\end{array}$ & $\%$ & $\begin{array}{l}\text { Suspect } \\
\text { (n) }\end{array}$ & $\%$ \\
\hline Single agents & 67 & $12.0^{\mathrm{a}}$ & 218 & $34.7^{\mathrm{a}}$ \\
\hline Di & 17 & 3.1 & 30 & 4.8 \\
\hline Ec & 14 & $2.5^{\mathrm{b}}$ & 47 & $7.5^{\mathrm{b}}$ \\
\hline $\mathrm{Bb}$ & 1 & 0.2 & 1 & 0.2 \\
\hline Ap & 16 & 2.9 & 20 & 3.2 \\
\hline $\mathrm{Li}$ & 19 & $3.4^{c}$ & 120 & $19.1^{c}$ \\
\hline Mixed agents & 11 & $2.0^{d}$ & 73 & $11.6^{\mathrm{d}}$ \\
\hline $\mathrm{Di}+\mathrm{Ec}$ & 0 & $0.0^{\mathrm{e}}$ & 6 & $0.9^{e}$ \\
\hline$D i+A p$ & 0 & 0.0 & 2 & 0.3 \\
\hline $\mathrm{Di}+\mathrm{Li}$ & 2 & 0.4 & 7 & 1.1 \\
\hline $\mathrm{Ec}+\mathrm{Bb}$ & 0 & 0.0 & 1 & 0.2 \\
\hline $\mathrm{Ec}+\mathrm{Ap}$ & 5 & $0.9^{f}$ & 20 & $3.1^{f}$ \\
\hline $\mathrm{EC}+\mathrm{Li}$ & 0 & $0.0^{9}$ & 17 & $2.7^{9}$ \\
\hline $\mathrm{Bb}+\mathrm{Li}$ & 0 & 0.0 & 1 & 0.2 \\
\hline$A p+L i$ & 0 & $0.0^{h}$ & 6 & $0.9^{h}$ \\
\hline $\mathrm{Di}+\mathrm{Ec}+\mathrm{Ap}$ & 1 & 0.2 & 6 & 0.9 \\
\hline $\mathrm{Di}+\mathrm{EC}+\mathrm{Li}$ & 0 & 0.0 & 3 & 0.5 \\
\hline $\mathrm{Di}+\mathrm{Ap}+\mathrm{Li}$ & 0 & 0.0 & 1 & 0.2 \\
\hline $\mathrm{Ec}+\mathrm{Ap}+\mathrm{Li}$ & 3 & 0.5 & 2 & 0.3 \\
\hline $\mathrm{Di}+\mathrm{Ec}+\mathrm{Ap}+\mathrm{Li}$ & 0 & 0.0 & 1 & 0.2 \\
\hline One or more agents & 78 & $14.0^{i}$ & 291 & $46.3^{i}$ \\
\hline
\end{tabular}

infantum; ${ }^{\text {a-i }}$ Statistically significant difference $(p<0.05)$. 
In healthy dogs, the highest percentage of $D$. immitis antigen-positive samples was obtained from Madeira (40\%), with a significant difference to the national average for heartworm (3.6\%; Table 1). The prevalence of D. immitis was not assessed in CVBD-suspect dogs from Madeira, but it is predictable that it would surpass the prevalence in the apparently healthy ones. In fact, non-detection of exposure to any other vector-borne agent under assessment strongly suggests that dirofilariosis is the major endemic CVBD in Madeira. In another investigation, Araujo [7] reported a prevalence of canine infection with heartworm microfilariae of $30 \%$ in Madeira, $16.5 \%$ in Alentejo and $12 \%$ in the Algarve. Prevalence may be underestimated if testing is only done for microfilariae and not also for heartworm antigen to reveal occult infection, i.e. adult nematode infection without circulating microfilariae [28,41]. Furthermore, canine filariae Acanthocheilonema dracunculoides and Acanthocheilonema reconditum exist in Portugal and their microfilariae need to be distinguished from those of $D$. immitis by morphological criteria, staining for acid phosphatase activity or PCR $[31,41]$. Cross-reactivity with $A$. dracunculoides or $A$. reconditum has not been reported for the heartworm antigen test kits. The rapid ELISA test used in the present study has shown to be highly specific, but sensitivity may decline in dogs with worm burdens of two heartworm females or less [41,42]. Under these circumstances, seropositivity of $D$. immitis antigen may underestimate the true prevalence of infection with the heartworm.

The seroprevalence of antibodies to E. canis was significantly higher in the apparently healthy dogs from the Algarve and in the CVBD-suspect ones from Alentejo (Tables 1 and 2). On the other hand, positivity to $E$. canis was significantly lower in the North and the Centre, although it reached regional levels of $7.6 \%$ and $9.0 \%$, respectively (Table 2). Molecular identification of $E$. canis by PCR and DNA sequencing has recently been reported in northeastern Portugal $[43,44]$ and in the Algarve [45]. The vector of E. canis, R. sanguineus, is the most prevalent tick species of dogs in Portugal and has been found throughout all the regions of the mainland [46]. Seropositivity to E. canis was identified as a risk factor for $D$. immitis in the suspect group, probably due to a coincidental higher exposure of E. canis-positive dogs to the heartworm (Table 4).

Seroprevalence to $B$. burgdorferi s. l. was the lowest countrywide. Evidence of exposure to the agent of Lyme disease was found in only one healthy dog from Alentejo (Table 1) and in three suspect dogs from the North, the Centre and Lisbon (Table 2). Antibodies to the spirochete were not detected in dogs either apparently healthy or CVBD-suspect from the Azores, the Algarve and Madeira. Nevertheless, DNA of B. burgdorferi s. 1. (genospecies B. burgdorferi sensu stricto, Borrelia garinii and Borrelia afzelii) has been detected in I. ricinus from Madeira [47]. In addition, B. burgdorferi s. 1. genospecies Borrelia lusitaniae was found in I. ricinus ticks from a sylvatic habitat in the southern part of the Lisbon region [48]. Other serological studies with IFATs in dogs revealed higher positivity levels in the north-eastern part of Portugal (12.7\%) [43] and the Algarve (2.3\%) [49]. Differences to the present study may be related with the subpopulations surveyed, which in the study conducted in the Northeast, exclusively comprised of rural and hunting dogs [43].

The seroprevalence of antibodies to Anaplasma spp. was significantly higher in the Algarve, for both healthy and suspect dogs, and lower in the Centre, but only for the latter (Tables 1 and 2). Serology has indicated the presence of $A$. phagocytophilum in wild rodents, horses, dogs and human beings in Portugal, although molecular evidence has only been achieved in one seropositive horse [50]. Additionally, two species of Ixodes were found to harbour A. phagocytophilum DNA: I. ricinus from Madeira and I. ventalloi from the southern part of Lisbon region [50]. On the other side, $A$. platys infections have been identified by PCR and DNA sequencing in dogs from the North [44] and in $A$. phagocytophilum-seropositive dogs from the Algarve [51]. Serological cross-reactivity between $A$. phagocytophilum and $A$. platys is likely to occur, but sensitivity of the in-clinic ELISA test for the detection of antibodies to A. platys still needs to be determined [34]. For specific identification of the canine Anaplasma pathogens it is useful to complement serological screening with molecular-based detection methods [38].

L. infantum-positive dogs were distributed throughout all the regions in the mainland, with prevalence being significantly higher in the CVBD-suspect animals. Antibodies to the protozoan were not detected in dogs from the Azores or from Madeira. The 4.3\% prevalence in the apparently healthy group (Table 1) is statistically similar to the $5.8 \%$ seroprevalence from another canine survey, with the DAT (direct agglutination test), in mainland Portugal [33]. In the present study, the percentage of Leishmania-positive clinically suspect dogs was higher $(p<0.001)$ than that of any other agent under assessment (Table 2). Seropositivity to L. infantum as a single agent was also significantly different between apparently healthy and clinically suspect dogs (Table 5). These findings suggest that L. infantum, either as a single or mixed pathogen, was the main cause of illness in dogs, among the vector-borne agents assessed. Nevertheless, they could also indicate that practitioners better recognise the clinical signs of leishmaniosis than those of other CVBDs. In fact, canine leishmaniosis is a common reason why dogs are brought into veterinary centres in Portugal [52]. 
Although the positivity of test results varied geographically, evidence of current or previous infection with at least one vector-borne agent was found in dogs from all the regions (Tables 1 and 2; Figure 1). Overall, a southerly trend of positivity to D. immitis, E. canis, Anaplasma spp., one or more agents and mixed agents was observed both in the apparently healthy and CVBD-suspect dogs. Differences in the regional seroprevalence levels of vector-borne agents are largely determined by the geographical distribution and local density of their arthropod vectors [53]. In the southern regions of the country (Alentejo, Lisbon, the Algarve and Madeira) climatic conditions might be more favourable to the proliferation and abundance of vectors. Nevertheless, there were still considerable levels of infection with or exposure to those agents and their combinations in the North and Centre. Travel histories were not available and the chance of dogs found positive in one region that were infected with or exposed to vector-borne pathogens in another region cannot be excluded.

Age above 12 months, an outdoor or mixed lifestyle and the non-use of ectoparasiticides were identified as risk factors for several dependent variables (Tables 3 and 4). Higher positivity levels for those defined variables are most likely related to an increased cumulative exposure of dogs to arthropod vectors and the agents they transmit. Both apparently healthy and CVBD-suspect dogs which received ectoparasiticides, i.e. commercially available acaricides and/or insecticides, had a significantly lower risk (OR) for positivity to one or more agents. In fact, infections with E. canis, B. burgdorferi, Anaplasma spp. and L. infantum can be prevented by the direct application on dogs of compounds with acaricidal/insecticidal and anti-feeding properties $[54,55]$. Besides preventing CVBDs, large spectrum ectoparasiticides also protect dogs from blood loss, local skin disorders and systemic toxicoses potentially caused by arthropod vectors [56]. Prevention of heartworm infection is widely attainable by chemoprophylaxis with macrocyclic lactones [38]. Preventative measures further comprise vaccines against a few CVBDs, including Lyme borreliosis and leishmaniosis $[13,20]$.

Although positive serological results may suggest prior exposure and not necessarily disease, they can alert veterinarians to take into consideration further clinical and diagnostic evaluation of individual dogs [57]. A significantly higher seropositivity to E. canis and L. infantum as single agents was found among CVBD-suspect dogs (Table 5). In addition, the four combinations of mixed agents with significantly higher seroreactivity in the suspect group included E. canis, L. infantum and D. immitis (Table 5). Furthermore, positivity to these agents, either as single or mixed pathogens, were identified as risk factors for clinical signs compatible with CVBDs. These observations firmly suggest that leishmaniosis, ehrlichiosis and dirofilariosis should be considered by practitioners in their diagnostic routine. The fact that some CVBD-suspect dogs were negative to the agents assessed raises the hypothesis that they were infected with other vector-borne pathogens, e.g. Babesia canis, Rickettsia conorii or Hepatozoon canis [25,31].

Many dogs infected with vector-borne agents remain asymptomatic for months or even years, but diagnosis of subclinical infection is important, as those animals might still serve as reservoirs of pathogens to other hosts including humans [2]. In areas of endemicity, an annual serological screening would be recommended to promote early detection and treatment.

\section{Conclusions}

In conclusion, the present study provides evidence that dogs in Portugal are at risk of becoming infected with vector-borne pathogens, some of which are of zoonotic concern. Although exposure can vary according to agent and geographical region, the likelihood of infection with at least one agent is considerable countrywide. In effect, CVBDs caused by single or mixed agents should be taken into account in the clinical management of canine patients. Moreover, prophylactic measures, including the use of ectoparasiticides against arthropods, must be put in place in order to protect dogs and simultaneously limit the risk of zoonotic transmission of vector-borne pathogens. Finally, this study is expected to give veterinary and public health authorities an increased awareness about the picture of CVBDs in Portugal with a view to establishing future control programs.

\section{Acknowledgements}

Authors thank the clinical directors, veterinary practitioners and staff of the 120 veterinary medical centres involved in this study. This work was supported by Bayer Portugal S.A., Animal Health Division.

\section{Author details}

1 Department of Veterinary Sciences, School of Agrarian and Veterinary Sciences, University of Trás-os-Montes e Alto Douro, Vila Real, Portugal. ${ }^{2}$ Parasite Disease Group, Instituto de Biologia Molecular e Celular (IBMC), Universidade do Porto, Portugal. ${ }^{3}$ Bayer Portugal S.A., Animal Health Division, Carnaxide, Portugal. ${ }^{4}$ Interdisciplinary Centre for Research in Animal Health (CIISA), Faculty of Veterinary Medicine, Technical University of Lisbon, Portugal.

\section{Authors' contributions}

CM conceived, designed and coordinated the field study; LC and LMdC participated in the study design and drafted the manuscript. All authors read and approved the final manuscript.

\section{Competing interests}

The authors declare that they have no competing interests.

Received: 11 January 2012 Accepted: 27 March 2012

Published: 27 March 2012 


\section{References}

1. Day MJ: One health: the importance of companion animal vector-borne diseases. Parasit Vectors 2011, 4:49.

2. Otranto D, Dantas-Torres F, Breitschwerdt EB: Managing canine vectorborne diseases of zoonotic concern: part one. Trends Parasitol 2009 25:157-163.

3. Day MJ: The immunopathology of canine vector-borne diseases. Parasit Vectors 2011, 4:48.

4. McCall JW, Genchi C, Kramer LH, Guerrero J, Venco L: Heartworm disease in animals and humans. Adv Parasitol 2008, 66:193-285.

5. Dantas-Torres F: Canine vector-borne diseases in Brazil. Parasit Vectors 2008, 1:25

6. Otranto D, Dantas-Torres F: Canine and feline vector-borne diseases in Italy: current situation and perspectives. Parasit Vectors 2010, 3:2.

7. Araujo AM: Canine and human Dirofilaria immitis infections in Portugal. A review [abstract]. Parassitologia 1996, 38(Suppl 1-2):366.

8. Irwin PJ, Jefferies R: Arthropod-transmitted diseases of companion animals in Southeast Asia. Trends Parasitol 2004, 20:27-34.

9. Shaw SE, Day MJ, Birtles RJ, Breitschwerdt EB: Tick-borne infectious diseases of dogs. Trends Parasitol 2001, 17:74-80.

10. Neer TM, Breitschwerdt EB, Greene RT, Lappin MR: Consensus statement on ehrlichial disease of small animals from the infectious disease study group of the ACVIM. J Vet Intern Med 2002, 16:309-315.

11. Harrus S, Bark H, Waner T: Canine monocytic ehrlichiosis: an update. Comp Cont Educ Pract Vet 1997, 19:431-444

12. Perez $M$, Bodor $M$, Zhang $C$, Xiong $Q$, Rikihisa $Y$ : Human infection with Ehrlichia canis accompanied by clinical signs in Venezuela. Ann N Y Acad Sci 2006, 1078:110-117.

13. Fritz CL: Emerging tick-borne diseases. Vet Clin Small Anim 2009, 39:265-278.

14. Steere AC: Lyme disease. N Engl J Med 2001, 345:115-125.

15. Littman MP, Goldstein RE, Labato MA, Lappin MR, Moore GE: ACVIM small animal consensus statement on Lyme disease in dogs: diagnosis, treatment, and prevention. J Vet Intern Med 2006, 20:422-434.

16. Alleman AR, Wamsley HL: An update on anaplasmosis in dogs. Vet Med 2008, 103:212-220.

17. Egenvall $A E$, Hedhammar AA, Bjoersdorff Al: Clinical features and serology of 14 dogs affected by granulocytic ehrlichiosis in Sweden. Vet Rec 1997 , 140:222-226.

18. Dumler JS, Choi KS, Garcia-Garcia JC, Barat NS, Scorpio DG, Garyu JW, Grab DJ, Bakken JS: Human granulocytic anaplasmosis and Anaplasma phagocytophilum. Emerg Infect Dis 2005, 11:1828-1834.

19. Harrus S, Aroch I, Lavy E, Bark H: Clinical manifestations of infectious canine cyclic thrombocytopenia. Vet Rec 1997, 141:247-250.

20. Solano-Gallego L, Miró G, Koutinas A, Cardoso L, Pennisi MG, Ferrer L, Bourdeau P, Oliva G, Baneth G: LeishVet guidelines for the practical management of canine leishmaniosis. Parasit Vectors 2011, 4:86.

21. Koutinas AF, Polizopoulou ZS, Saridomichelakis MN, Argyriadis D, Fytianou A, Plevraki KG: Clinical considerations on canine visceral leishmaniasis in Greece: a retrospective study of 158 cases (1989-1996). J Am Anim Hosp Assoc 1999, 35:376-383.

22. Molina R, Amela C, Nieto J, San-Andrés M, González F, Castillo JA, Lucientes J, Alvar J: Infectivity of dogs naturally infected with Leishmania infantum to colonized Phlebotomus perniciosus. Trans $R$ Soc Trop Med Hyg 1994, 88:491-493

23. Desjeux P: Worldwide increasing risk factors for leishmaniasis. Med Microbiol Immunol 2001, 190:77-79.

24. Palatnik-de-Sousa CB, Day MJ: One Health: the global challenge of epidemic and endemic leishmaniasis. Parasit Vectors 2011, 4:197.

25. Cardoso L, Yisaschar-Mekuzas Y, Rodrigues FT, Costa A, Machado J, DizLopes D, Baneth G: Canine babesiosis in northern Portugal and molecular characterization of vector-borne co-infections. Parasit Vectors 2010, 3:27.

26. Gaunt S, Beall M, Stillman B, Lorentzen L, Diniz P, Chandrashekar R, Breitschwerdt E: Experimental infection and co-infection of dogs with Anaplasma platys and Ehrlichia canis: hematologic, serologic and molecular findings. Parasit Vectors 2010, 3:33.

27. Bowman D, Little SE, Lorentzen L, Shields J, Sullivan MP, Carlin EP: Prevalence and geographic distribution of Dirofilaria immitis, Borrelia burgdorferi, Ehrlichia canis, and Anaplasma phagocytophilum in dogs in the United States: results of a national clinic-based serologic survey. Vet Parasitol 2009, 160:138-148.
28. Otranto D, Dantas-Torres F, Breitschwerdt EB: Managing canine vectorborne diseases of zoonotic concern: part two. Trends Parasitol 2009 25.228-235.

29. Casimiro E, Calheiros J, Santos FD, Kovats S: National assessment of human health effects of climate change in Portugal: approach and key findings. Environ Health Perspect 2006, 114:1950-1956.

30. Gray JS, Dautel H, Estrada-Peña A, Kahl O, Lindgren E: Effects of climate change on ticks and tick-borne diseases in Europe. Interdiscip Perspect Infect Dis 2009, 2009:593232.

31. Menn B, Lorentz S, Naucke TJ: Imported and travelling dogs as carriers of canine vector-borne pathogens in Germany. Parasit Vectors 2010, 3:34.

32. Seixas R, Alho AM, Guerra D, Madeira de Carvalho L: Doenças caninas de transmissão vectorial: uma picada com muitas consequências! Vet Med 2011, 77: 23-46.

33. Maia C, Campino L, Marques M, Cristóvão J, Ramada J, Neves R, Cardoso L, Cortes S: "A semana da leishmaniose" - ONLeish. Resultados preliminares. Acta Parasitol Port 2009, 16:22-23.

34. Chandrashekar R, Mainville CA, Beall MJ, O'Connor T, Eberts MD, Alleman AR, Gaunt SD, Breitschwerdt EB: Performance of a commercially available in-clinic ELISA for the detection of antibodies against Anaplasma phagocytophilum, Ehrlichia canis, and Borrelia burgdorferi and Dirofilaria immitis antigen in dogs. Am J Vet Res 2010, 71:1443-1450.

35. O'Connor TP, Hanscom JL, Hegarty BC, Groat RG, Breitschwerdt EB: Comparison of an indirect immunofluorescence assay, western blot analysis, and a commercially available ELISA for detection of Ehrlichia canis antibodies in canine sera. Am J Vet Res 2006, 67:206-210.

36. Philipp MT, Bowers LC, Fawcett PT, Jacobs MB, Liang FT, Marques AR, Mitchell PD, Purcell JE, Ratterree MS, Straubinger RK: Antibody response to IR6, a conserved immunodominant region of the VIsE lipoprotein, wanes rapidly after antibiotic treatment of Borrelia burgdorferi infection in experimental animals and in humans. J Infect Dis 2001, 184:870-878

37. O'Connor TP, Esty KJ, Hanscom JL, Shields P, Philipp MT: Dogs vaccinated with common Lyme disease vaccines do not respond to IR6, the conserved immunodominant region of the VIsE surface protein of Borrelia burgdorferi. Clin Diagn Lab Immunol 2004, 11:458-462.

38. Lim S, Irwin PJ, Lee S, Oh M, Ahn K, Myung B, Shin S: Comparison of selected canine vector-borne diseases between urban animal shelter and rural hunting dogs in Korea. Parasit Vectors 2010, 3:32

39. Ferroglio E, Centaro E, Mignone W, Trisciuoglio A: Evaluation of an ELISA rapid device for the serological diagnosis of Leishmania infantum infection in dog as compared with immunofluorescence assay and Western blot. Vet Parasitol 2007, 144:162-166.

40. Petrie A, Watson P: Statistics for Veterinary and Animal Science Oxford: Blackwell; 1999.

41. Pantchev N, Schaper R, Limousin S, Norden N, Weise M, Lorentzen L: Occurrence of Dirofilaria immitis and tick-borne infections caused by Anaplasma phagocytophilum, Borrelia burgdorferi sensu lato and Ehrlichia canis in domestic dogs in France: results of a countrywide serologic survey. Parasitol Res 2009, 105(Suppl 1):S101-114.

42. Atkins CE: Comparison of results of three commercial heartworm antigen test kits in dogs with low heartworm burdens. J Am Vet Med Assoc 2003, 222:1221-1223.

43. Figueiredo TCD: Estudo da prevalência de doenças associadas a vectores em canídeos domésticos do distrito de Bragança. MSC dissertation Lisbon University, Faculty of Medicine; 2008.

44. Cardoso L, Tuna J, Vieira L, Yisaschar-Mekuzas Y, Baneth G: Molecular detection of Anaplasma platys and Ehrlichia canis in dogs from the North of Portugal. Vet J 2008, 183:232-233.

45. Alexandre N, Santos AS, Núncio MS, Sousa R, Boinas F, Bacellar F: Detection of Ehrlichia canis by polymerase chain reaction in dogs from Portugal. Vet J 2009, 181:343-344.

46. Caeiro V: General review of tick species present in Portugal. Parassitologia 1999, 41(Suppl 1):11-15.

47. Matuschka F-R, Klug B, Schinkel TW, Spielman A, Richter D: Diversity of European Lyme disease spirochetes at the southern margin of their range. Appl Environ Microbiol 1998, 64:1980-1982.

48. De Michelis S, Sewell HS, Collares-Pereira M, Santos-Reis M, Schouls LM, Benes V, Holmes EC, Kurtenbach K: Genetic diversity of Borrelia burgdorferi sensu lato in ticks from mainland Portugal. J Clin Microbiol 2000, 38:2128-2133. 
49. Alexandre NML: Estudo clínico e epidemiológico da febre botonosa, ehrlichiose canina e borreliose de Lyme numa população de canídeos domésticos do Algarve. MSc dissertation Technical University of Lisbon, Faculty of Veterinary Medicine; 2006.

50. Santos AS, Bacellar F, Dumler JS: A 4-year study of Anaplasma phagocytophilum in Portugal. Clin Microbiol Infect 2009, 15(Suppl 2):46-47.

51. Santos AS, Alexandre N, Sousa R, Núncio MS, Bacellar F, Dumler JS: Serological and molecular survey of Anaplasma species infection in dogs with suspected tickborne disease in Portugal. Vet Rec 2009, 164:168-171.

52. Cardoso L, Mendão C: Inquérito sobre a leishmaniose canina em Portugal - resultados preliminares. Vet Med 2009, , 52: 57-62.

53. Dantas-Torres F: Biology and ecology of the brown dog tick, Rhipicephalus sanguineus. Parasit Vectors 2010, 3:26.

54. Otranto D, de Caprariis D, Lia RP, Tarallo V, Lorusso V, Testini G, DantasTorres F, Latrofa S, Diniz PP, Mencke N, Maggi RG, Breitschwerdt E, Capelli G, Stanneck D: Prevention of endemic canine vector-borne diseases using imidacloprid $10 \%$ and permethrin $50 \%$ in young dogs: a longitudinal field study. Vet Parasitol 2010, 172:323-332.

55. McCall JW, Baker CF, Mather TN, Chester ST, McCall SD, Irwin JP, Young SL, Cramer LG, Pollmeier MG: The ability of a topical novel combination of fipronil, amitraz and (S)-methoprene to protect dogs from Borrelia burgdorferi and Anaplasma phagocytophilum infections transmitted by Ixodes scapularis. Vet Parasitol 2011, 179:335-342.

56. Cardoso L: Dogs, arthropod-transmitted pathogens and zoonotic diseases. Trends Parasitol 2010, 26:61-62.

57. Carrade D, Foley J, Sullivan M, Foley CW, Sykes JE: Spatial distribution of seroprevalence for Anaplasma phagocytophilum, Borrelia burgdorferi, Ehrlichia canis, and Dirofilaria immitis in dogs in Washington, Oregon, and California. Vet Clin Pathol 2011, 40:293-302.

doi:10.1186/1756-3305-5-62

Cite this article as: Cardoso et al.: Prevalence of Dirofilaria immitis, Ehrlichia canis, Borrelia burgdorferi sensu lato, Anaplasma spp. and Leishmania infantum in apparently healthy and CVBD-suspect dogs in Portugal - a national serological study. Parasites \& Vectors 2012 5:62.

\section{Submit your next manuscript to BioMed Central and take full advantage of:}

- Convenient online submission

- Thorough peer review

- No space constraints or color figure charges

- Immediate publication on acceptance

- Inclusion in PubMed, CAS, Scopus and Google Scholar

- Research which is freely available for redistribution

Submit your manuscript at www.biomedcentral.com/submit
C Biomed Central 